\title{
ALTERATION MINERALS EXTRACTION USING AIRBORNE HYPERSPECTRAL DATA CASI AND SASI IN WUYI METALLOGENIC BELT, CHINA
}

\author{
Zhaoqiang Huang ${ }^{1}$, Jianchun Zheng ${ }^{2}$ \\ ${ }^{1}$ Institute of Mineral Resources, China Metallurgical Geological Bureau, Beijing 101300, China - hzhaoq@126.com \\ ${ }^{2}$ Beijing Research Center of Urban System Engineering, Beijing 100035, China - zheng_jianchun@sina.com
}

KEY WORDS: Alteration Minerals, Airborne Hyperspectral, Wuyi Metallogenic Belt, Spectral Feature, MTMF, CASI and SASI

\begin{abstract}
:
Hydrothermal alteration is an important content in the study of epithermal deposit, and its deep part is often accompanied by porphyry mineralization. The objective of research is to mapping the alteration minerals for mineral exploration using mixture tuned matched filtering (MTMF) approach based on airborne hyperspectral data CASI and SASI in Wuyi metallogenic belt, China, which has complex geological structure and excellent mineralization conditions and high regional forest coverage rate. Gold mineralization is closely related to the Yanshan period epithermal intrusive rocks, and often exists in external contact zone of allgovite, monzomite porphyrite, granite porphyry, quarz porphyry, et al.. The main mineral alteration types include silicification (quartz), sericitization (sericite, illite), pyritization (pyrite), chloritization (chlorite), and partial calcitization (calcite). The alteration minerals extraction based on integrated CASI_SASI reflectance data were processed by MTMF algorithm with the input imagery which was pre-processed by MNF and the input endmember spectra measured by SVC spectrometer to performs MF and add an infeasibility image. The MTMF results provide an estimate to mineral subpixel fractions leading to the abundances of alteration minerals at each pixel and alteration minerals distribution. The accuracy of alteration mineral extraction refers to the extent which it agrees with a set of reference data measured in the field reconnaissance. So the CASI_SASI airborne hyperspectral image provides the efficient way to map the detailed alteration minerals distribution for mineral exploration in high forest coverage area.
\end{abstract}

\section{INTRODUCTION}

Spectroscopy is the measurement of a light as a function of wavelength reflected from a material. Hydrothermal alteration is an important content in the study of epithermal deposit, and its deep part is often accompanied by porphyry mineralization. In the early 1980s, the concept of imaging spectrometry, or hyperspectral imaging of the Earth, originated at the NASA Jet Propulsion Laboratory (JPL) (Pu et al., 2000). Imaging spectrometers acquire images in many contiguous spectral channels, which is typical to the laboratory or in situ reflectance measurements, such that for each picture element (pixel) a complete reflectance or emittance spectrum can be derived from the wavelength region covered (Goetz et al., 1985). Bandwidths and sampling greater than $25 \mathrm{~nm}$ rapidly lose the ability to resolve important mineral absorption features. Spectroscopy is too sensitive to small changes in the chemistry and/or structure of a material. So the narrower the spectral bandwidth, the narrower the absorption feature the spectrometer will accurately measure, if enough adjacent spectral samples are obtained (Clark, 1999). In many cases spectroscopy is very sensitive to subtle changes in crystal structure or chemistry for some materials, and spectroscopy is an excellent tool not only for detecting certain chemistries, but also at abundance levels unmatched by other tools (Clark, 1999). The reflectance spectra of ground objects provides abundant information about many important earth-surface minerals in the solar spectral range 400-2500 nm (Clark et al., 1990). So the visible near infrared (VNIR, spectral range 400$1000 \mathrm{~nm}$ ) and shortwave infrared (SWIR, spectral range 1000$2500 \mathrm{~nm}$ ) spectral range covers main spectral features of iron- bearing minerals, hydroxyl-bearing minerals, sulfates, and carbonates.

There have been many methods developed for the analysis of hyperspectral data. The approaches which measure similarity between targets include Spectral Angle Mapper (SAM), Spectral Information Divergence (SID), Matched Filtering (MF), Mixture Tuned Matched Filtering (MTMF) and Constrained Energy Minimization (CEM), etc. In this research, MTMF method was used for alteration minerals classification.

The CASI and SASI airborne hyperspectral sensors, which were produced by the Canadian company ITRES, include CASI-1500 and SASI-600 sensors. The CASI-1500 and SASI600 scanners acquired spectrums in the wavelength ranges of $380-1050 \mathrm{~nm}$ and $950-2450 \mathrm{~nm}$, with 72 and 100 bands, respectively. The scanners were flown over the study area on December 8th, 2017, between 11:00 and 14:30. The survey was flown at a height of $2 \mathrm{~km}$. The spatial resolution of CASI data is $1 \mathrm{~m}$ by $1 \mathrm{~m}$, and that of the SASI is $2.4 \mathrm{~m}$ by $2.4 \mathrm{~m}$.

The objective of research is to mapping the alteration minerals for mineral exploration using mixture tuned matched filtering (MTMF) approach based on airborne hyperspectral data CASI and SASI in Wuyi metallogenic belt, China.

\section{GEOLOGY OF THE STUDY AREA}

Wuyi Dehua-Youxi-Yongtai ore district (Figure 1) is located in central Fujian Province, the intersection part of Daiyunshan

\footnotetext{
* Corresponding author
} 
giant ring volcano tectonic (northwest) in the magmatic arc of the southeast coast of China and Northwest Fujian metamorphic belt, and has experienced a complex multi stage structure-magma-metallogenic evolution history, and has complex geological structure and excellent mineralization conditions. Based on the tectonic erosion terrain, the mountains generally move towards the NE and NNE. And regional forest coverage rate is high. There are rich mineral resources, such as gold, kaolin, copper, lead and zinc, etc. The main types of ore deposits are volcano-subvolcano hydrothermal type (porphyry), in addition to the metamorphic clastic rock hydrothermal type, tectonic hydrothermal type. From the Proterozoic to Mesozoic region stratigraphic, which were main metamorphic rocks and Mesozoic volcano rocks, were observed. The exposed metamorphic base and Mesozoic volcanic rocks generally have high Au abundance. In the area, magma intrusive activities were frequent. Gold mineralization is closely related to the Yanshan period epithermal intrusive rocks, and often exists in external contact zone of allgovite, monzomite porphyrite, granite porphyry, quarz porphyry, et al.. The main mineral alteration types include silicification (quartz), sericitization (sericite, illite), pyritization (pyrite), chloritization (chlorite), and partial calcitization (calcite). Silicification has spectral absorption features at 2195nm (main) and $1468 \mathrm{~nm}$. Sericitization has spectral absorption features at $2200 \mathrm{~nm}$ (main) and $2345 \mathrm{~nm}$. Pyritization has spectral absorption feature at $1000 \mathrm{~nm}$ with a broad band. And chloritization has spectral absorption features at $2325 \mathrm{~nm}$ (main) and $2245 \mathrm{~nm}$ (secondary) and $2115 \mathrm{~nm}$ (weak). Calcitization has spectral absorption features at $2345 \mathrm{~nm}$ (main) and $2165 \mathrm{~nm}$ (secondary).

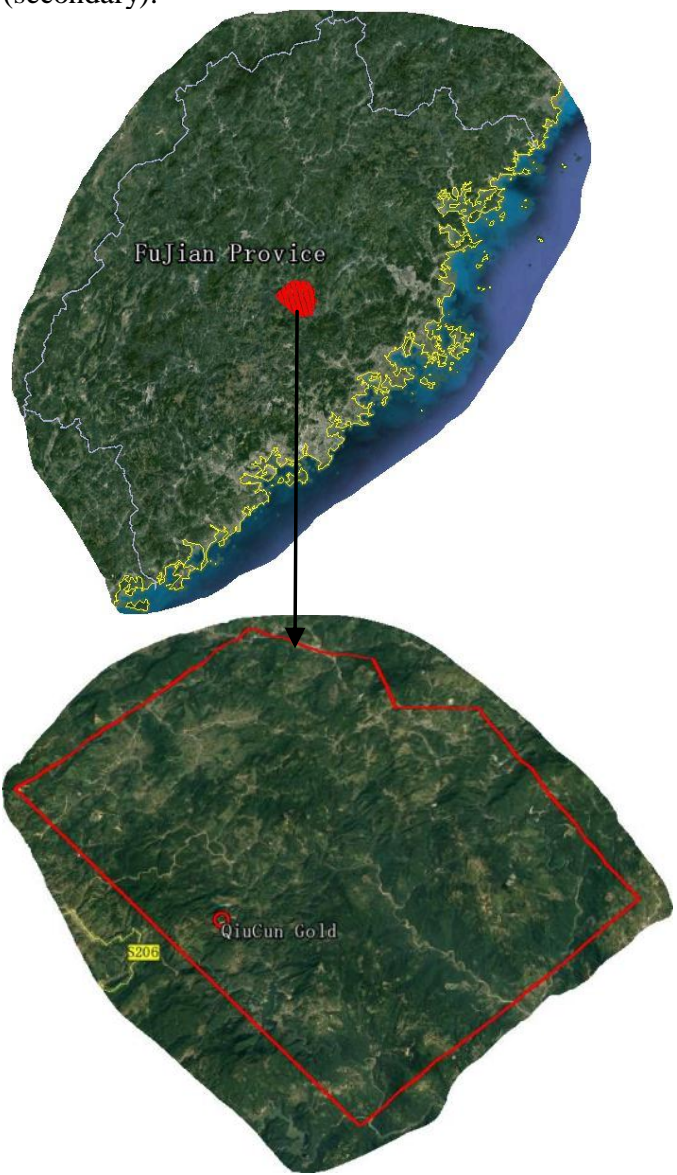

Figure 1. Location map of study area

\section{HYPERSPECTRAL DATA AND METHOD}

\subsection{CASI_SASI Hyperspectral Data}

The CASI and SASI hyperspectral data were acquired on December $8^{\text {th }}-20^{\text {th }}, 2017$, between 11:00 and 14:30. The SASI data were geometrically corrected to register to the CASI data by ground control points and using a second-degree polynomial warp with nearest neighbor resampling and CASI data were spatially resampled to $2.4 \mathrm{~m}$ by $2.4 \mathrm{~m}$, which is equal to the SASI data using the nearest neighbour method, and then CASI and SASI bands were layered together to form a CASI_SASI data set in $2.4 \mathrm{~m}$ spatial resolution. In the hyperspectral remote sensing data, the spectral range from 1356 to $1417 \mathrm{~nm}$ and 1820 to $1932 \mathrm{~nm}$ is greatly influenced by water vapour, and these bands contain little ground information. Therefore, there bands need to be removed. For SASI data, the bands affected by water vapour are 28 30, 59 65 bands. After eliminating these bands affected by water vapour, SASI has 90 remaining bands. In addition, the several CASI bands were overlapped with some SASI bands. Because the noise of CASI part is higher than the SASI's and the radiation value is too low, the CASI part (10 bands between $959-1045 \mathrm{~nm}$ ) is removed. So the last CASI_SASI dataset has 152 bands.

Atmospheric correction algorithms for producing surface reflectance from imaging spectrometer data include Highaccuracy ATmospheric Correction for Hyperspectral Data (HATCH) (Qu et al., 2003), Atmosphere CORrection Now (ACORN) (Kruse, 2004), Fast Lineof-sight Atmospheric Analysis of Spectral Hypercubes (FLAASH) (Adler-Goldenet al., 1999), Imaging Spectrometer Data Analysis System (ISDAS) (Staenz et al., 1998), and a series of Atmospheric and Topographic Correction (ATCOR) codes (Richter, 1996, 1998; Ritcher and Schlaepfer, 2002). In this research, the CASI_SASI data set was processed using FLAASH (Fast lineof-sight Atmospheric Analysis of Spectral Hypercubes) atmospheric correction module (Adler-Golden, 1998; Kruse, 2004) to produce the reflectance data. FLAASH is a MODTRAN-based atmospheric correction module developed jointly by the Air Force Phillips Lab-oratory, Hamscon AFB and Spectral Sciences, Inc. (Adler-Goldenet al., 1999). FLAASH software retrieved atmospheric water vapor and optical depth of aerosol pixel-by-pixel using the methods of Gao et al. (1993, 2009) and Kaufmann et al. (1997). The water vapour wavelength $1135 \mathrm{~nm}$ was selected to retrieve atmospheric water.

The MNF algorithm was used to transform the data to determine the inherent dimensionality of the imagery and reduce the computational requirements for subsequent processing. Higher eigenvalues generally indicate higher information content. The top MNF bands for CASI_SASI dataset (corresponding to the approximate dimensionality) contain most of the spectral information (Green, et al., 1998). In the study area, the MNF analysis eigenvalue indicated a dimensionality of approximately 20 (Figure 2, Figure 3 ). And for evaluating the value of CASI_SASI data, the Inverse MNF algorithm was carried out using the top $20 \mathrm{MNF}$ bands. The result of comparing the spectral used FLAASH with the spectral used Inverse MNF (Figure 4), indicated that the CASI_SASI dataset was the high quality data and has a small amount noise. 


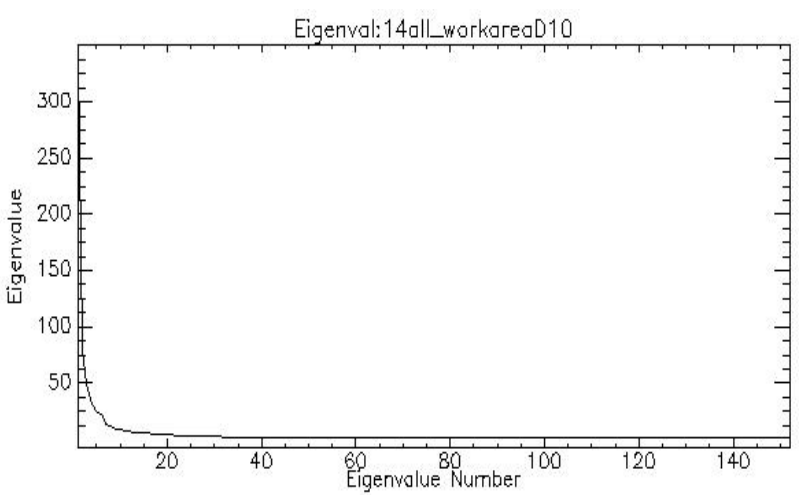

Figure 2. MNF Eigenvalue

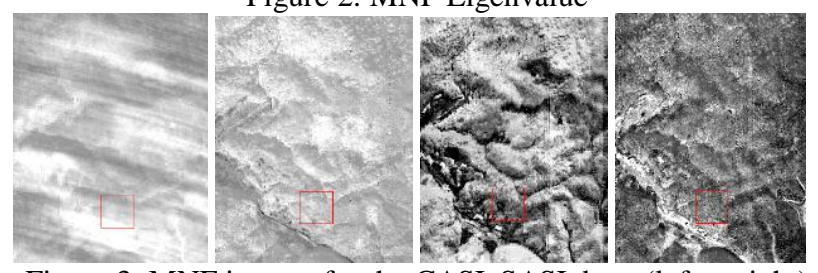

Figure 3. MNF images for the CASI_SASI data. (left to right) MNF band 1, MNF band 5, MNF band 10, MNF band 20

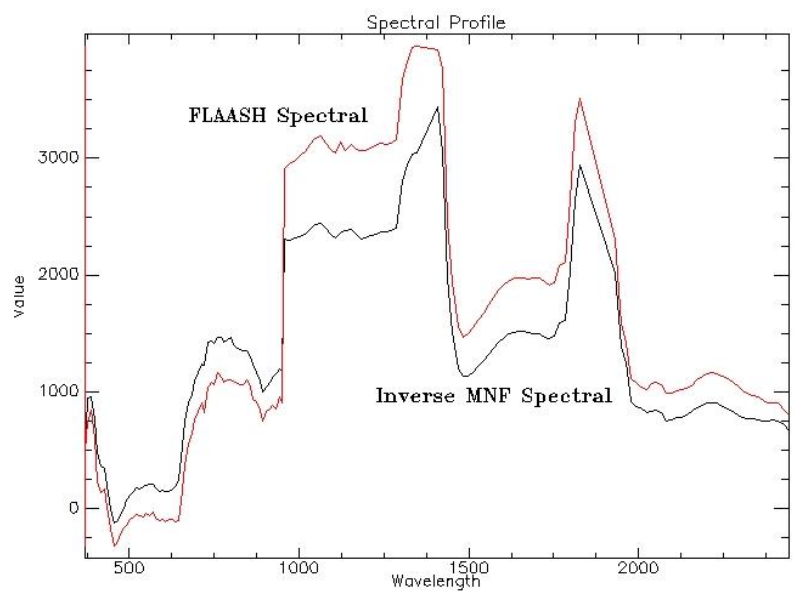

Figure 4. Comparison between spectral used FLAASH and spectral used Inverse MNF

\subsection{Ground Spectral Data}

In the study area, the typical rock spectra were measured under cloudless condition between 10:00 and 14:00 by SVC-HR1024 field spectrometer (Spectral Visual Co., USA) which has a spectral range $350-2500 \mathrm{~nm}$ and resolution less than $2 \mathrm{~nm}$ in range $350-1000 \mathrm{~nm}$, less than $4 \mathrm{~nm}$ in range $1000-1850$ and less than $3 \mathrm{~nm}$ in range $1850-2500 \mathrm{~nm}$. This spectrometer was fitted with $25^{\circ}$ field of view fiber optics and $1 \mathrm{~ms}$ minimum integral time.

The main altered minerals spectra were measured, which included kaolinite, muscovite, calcite, phengite, paragonite and chlorite (Figure 5). And the six spectra were transformed using MNF for mineral information extraction.

The field samples spectra analysis results were shown in Figure 6 . There is a circle volcanic structure in the middle of the figure 6 . The altered mineral chlorite mainly distributed on the eastern of the circle volcanic structure. And kaolinite mainly appeared on the northern of the circle volcanic structure, muscovite presented from west to east, and phengite mainly located on the north-east site.

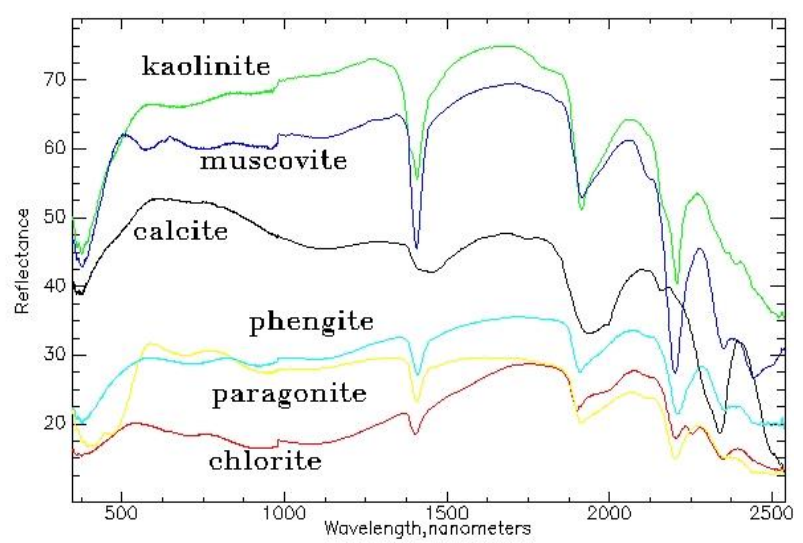

Figure 5. Field rock spectra measured by SVC spectrometer

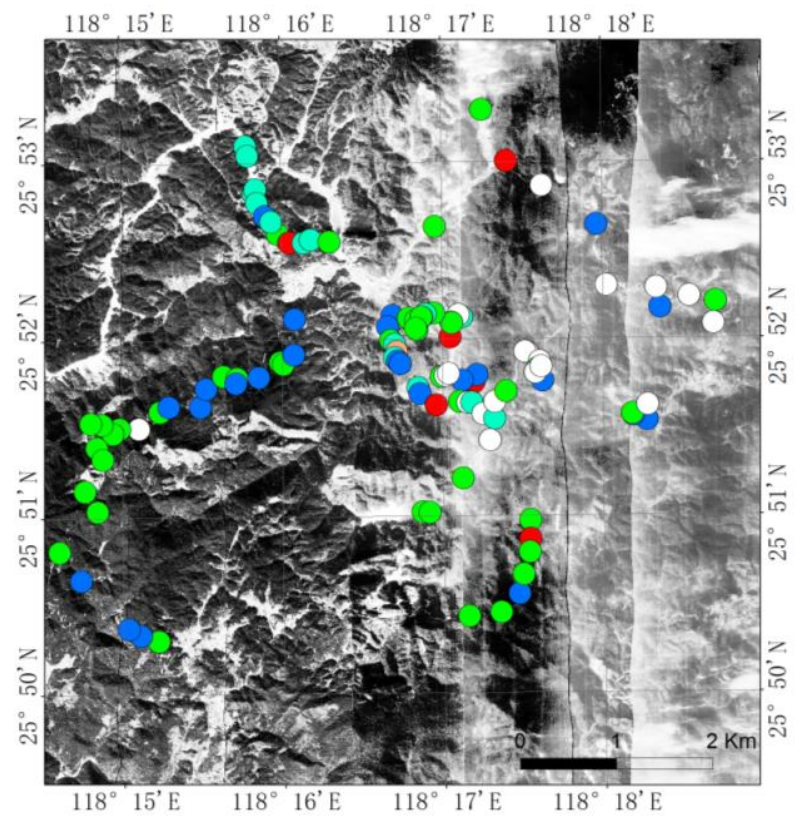

Figure 6. Field sample altered mineral map (magenta for calcite, white for chlorite, red for kaolinite, blue for muscovite, green for illite, cyan for phengite)

To ensure the accuracy of the CASI_SASI data, its spectral absorption feature were extracted to compare to the field spectra (Figure 7). Figure 7 showed the rock spectra which included chlorite and muscovite alteration minerals, kaolinite and muscovite alteration minerals. This indicated that the CASI_SASI spectral feature was good matched with the field spectral feature. 

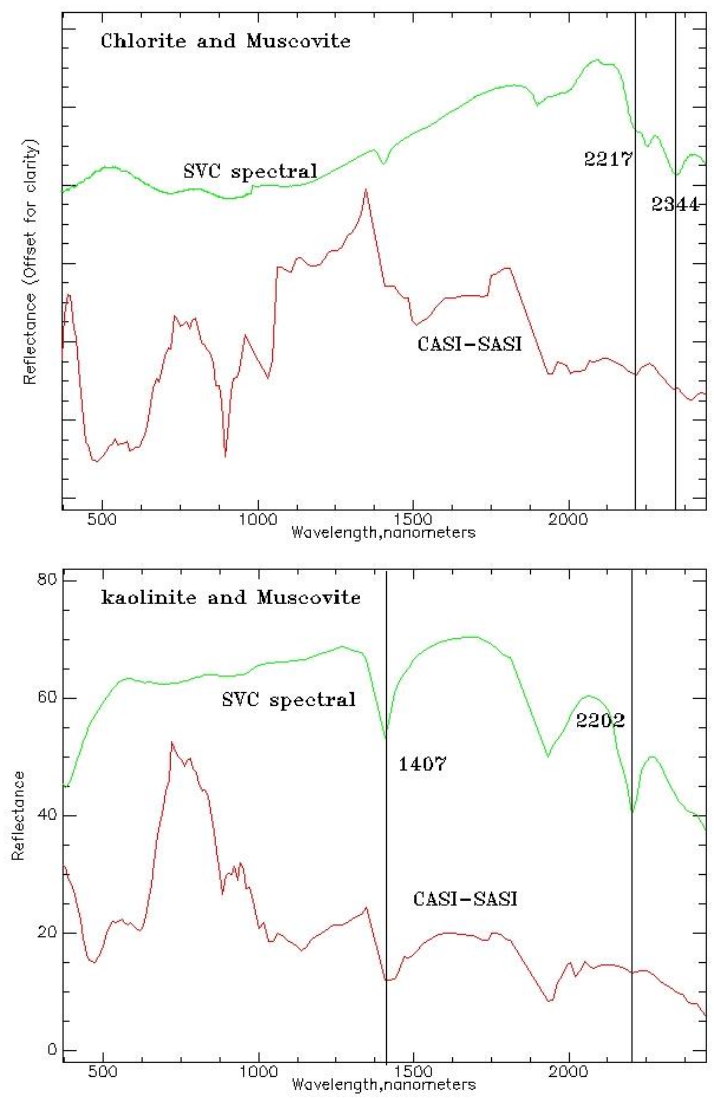

Figure 7. Comparison between CASI_SASI spectral feature and SVC spectral feature

\subsection{Method}

Methods for analysis of hyperspectral data that allow reproducible results with minimal subjective analysis are implemented and documented within the "Environment for Visualizing Images" (ENVI) software system originally developed by Analytical Imaging and Geophysics LLC (AIG) scientists (Kruse, et al., 2000; ITT, 2009). AIG-developed hyperspectral analysis methods include spectral polishing, spectral data reduction using the MNF transformation, spatial data reduction using the Pixel Purity Index (PPI), an nDimensional Visualizer to determine image endmembers, identification of endmembers using their reflectance spectra in the Spectral Analyst, and mineral mapping using MixtureTuned Matched Filtering(MTMF). In this study, the endmembers utilize the field spectra measured by SVC spectrometer.

MTMF is a partial sub-pixel unmixing method which combines the strength of the MF method (no requirement to know all the end-members) with physical constraints imposed by mixing theory. MTMF performs MF and add an infeasibility image to the results. The infeasibility image is used to reduce the number of false positives that are sometimes found when using MF. Pixels with a high infeasibility are likely to be MF false positives. Correctly mapped pixels will have an MF score above the background distribution around zero and a low infeasibility value. The output from MTMF is a set of rule images corresponding to both the MF score and the infeasibility score for each pixel compared to each endmember spectrum (two rule images per endmember). The MF floatingpoint results help estimate the relative degree of match to the reference spectrum and the approximate sub-pixel abundance, where 1.0 is a perfect match. Correctly mapped pixels have an MF score above the background distribution, which has some noise-limited spread around zero, and a low infeasibility value (ITT, 2009). And the matched alteration minerals maps were filtered by Median Filter 3X3.

\section{DISCUSSION}

The alteration mineral map was produced by applying MTMF method to CASI_SASI data using the main field rock spectra. Hyperspectral data have been called a "virtual verification", due to their high spectral resolution (King and Clark, 2000). In the map (figure 7), the coloured pixels representing the different alteration minerals were overlaid on a grayscale background image. The results indicated the distribution of alteration minerals around the ring volcano tectonic. But some alteration information may be error because the shape or forest, which need to re-extract the information after removing the effects of shape or forest.

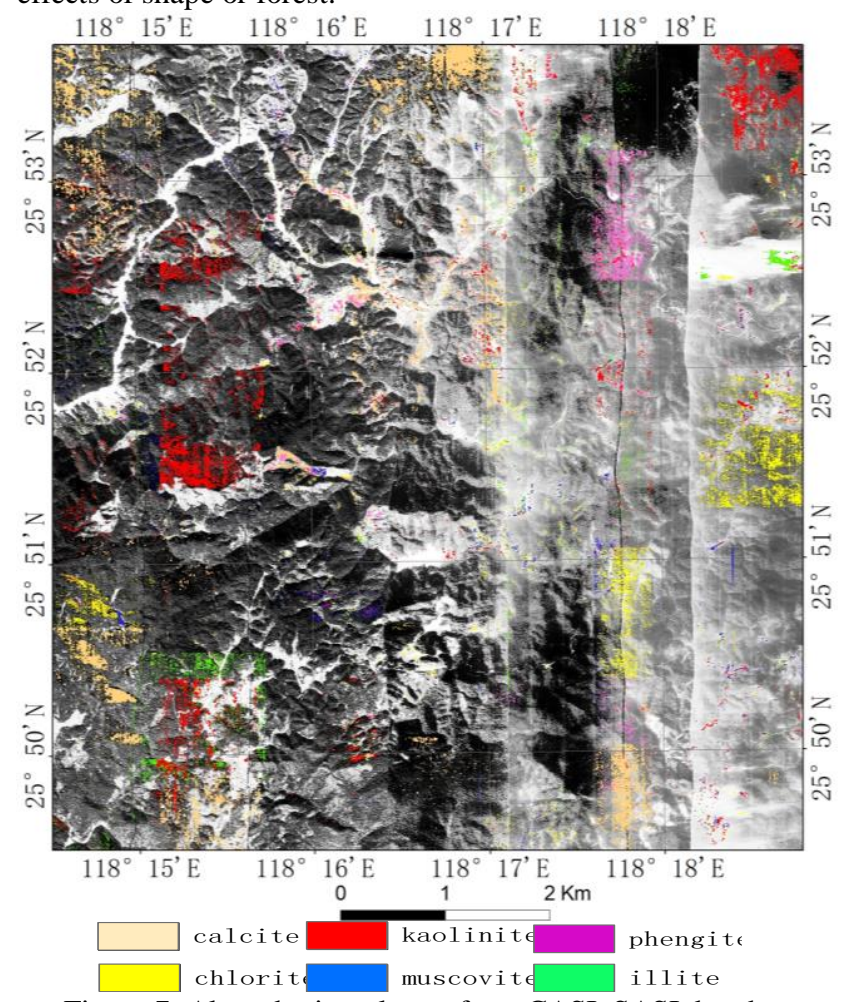

Figure 7. Altered mineral map from CASI_SASI data by MTMF

\section{CONCLUSIONS}

CASI_SASI hyperspectral data can provide the efficient way to map the detailed alteration minerals distribution for mineral exploration in high forest coverage area. But some methods such as accuracy correction of atmospheric water vapour and shapes and forest effects to apparent reflection, need to be developed in future.

\section{ACKNOWLEDGEMENTS (OPTIONAL)}

This work is supported by the National Key R\&D Program of China (2016YFC0600210) and the National Natural Science Foundation of China (41272366). 


\section{REFERENCES}

Adler-Golden, S., Berk, A., Bernstein, L. S., \& Richtsmeier, S. 1998. FlAASH, A MODTRAN4 atmospheric correction package for hyperspectral data retrievals and simulations. Summaries of the seventh JPL airborne earth science workshop JPL-Pub., vol. 97-21 (pp.1-9). Pasadena, CA: JPL Pub.

Adler-Golden, S.M., Mattchew, M.W., Bemstein, S., Levine, R.Y., Berk, A., Richtsmeier,S.C., 1999. Atmospheric correction for short-wave spectral imagery based on MODTRAN4. In: Grenn, R.O. (Ed.), Summaries of the Eighth JPL Airborne EarthScience Workshop JPL Publication, Bol. 99-17. Jet Propul. Lab. 1, Pasadena, CA, pp. 21-29.

Clark, R. N., 1999. Chapter 1: Spectroscopy of Rocks and Minerals, and Principles of Spectroscopy, in Manual of Remote Sensing, Volume 3, Remote Sensing for the Earth Sciences, (A.N. Rencz, ed.) John Wiley and Sons, New York, p 3- 58.

Clark, R.N., King, T.V.V., Klejwa, M., Swayze, G.A., 1990. High spectral resolution spectroscopy of minerals. Journal of Geophysical Research, 95(8), 12653-12680.

Gao, B.C., Heidebrecht, K.B., Goetz, A.F.H., 1993. Derivation of scaled surface reflectances from AVIRIS data. Remote Sens. Environ. 44, 165 - 178.

Gao, B.C., Montes, M.J., Davis, C.O., Goetz, A.F.H., 2009. Atmospheric correction algorithms for hyperspectral remote sensing data of land and ocean. Remote Sens.Environ. 113, S17 - S24.

Green, A. A., Berman, M., Switzer, B. and Craig, M. D.. 1998. A transformation for ordering multispectral data in terms of image quality with implications for noise removal. IEEE Trans. Geosci. Remote Sensing, vol. 26, pp. 65-74, Jan.

Goetz, A. F. H., Vane, G., Solomon, J., Rock, B. N. 1985. Imaging spectrometry for Earth remote sensing. Science, 228, $1147-1153$

ITT Visual Information Solutions (ITT VIS), 2009. ENVI Help, ENVI Software Package. ver.4.7.

Kaufmann, Y.J., Wald, A.E., Remer, L.A., Gao, B.C., Li, R.R., Flynn, L., 1997. The MODIS2.1-_m channel-correction with visible reflectance for use in remote sensing of aerosol. IEEE Trans. Geosci. Remote Sens. 35, 1286-1298.

King, T.V., Clark, R., 2000. Verification of remotely sensed data. In: Kuehn, F., King, T.V., Hoerig, B., Peters, D. (Eds.), Remote Sensing for Site Characterization. Springer, Berlin Heidelberg, pp. 59-62.

Kruse, F. A. 2004. Comparison of ATREM, ACORN, and FLAASH atmosphericcorrections using low-altitude AVIRIS data of Boulder, CO. Summaries of 13th JPLAirborne Geoscience Workshop, Jet Propulsion Lab, Pasadena, CA.

Kruse, F. A., Boardman, J.W., 2000. Characterization and mapping of Kimberlites and related diatremes using hyperspectral remote sensing. in Proc. 2000 IEEE AeroSpace Conf., Big Sky, MO, Mar. 18-24

PU Ruiliang, GONG Peng. 2000. Hyperspectral Remote Sensing and Applications. Beijing: Higher Education Press.

Qu, Z., Kindel, B.C., Goetz, A.F.H., 2003. The high accuracy atmospheric correction for hypersepctral data (HATCH) model. IEEE Trans. Geosci. Remote Sens. 41,1223 - 1231.

Richter, R., 1996. Atmospheric correction of DAIS Hyperspectral image data. Comput.Geosci. 22, 785 - 793.

Richter, R., 1998. Correction of satellite imagery over mountainous terrain. Appl.Opt. 37, 4004 - 4015.

Ritcher, R., Schlaepfer, D., 2002. Geo-atmospheric processing of airborne imaging spectrometry data. Part 2: atmospheric/topographic correction. Int. J. Remote Sens. 23 (13), $2631-2649$.

Staenz, K., Szeredi, T., Schwarz, J., 1998. ISDAS-a system for processing/analysing hyperspectral data. Can. J. Remote Sens. $24,99-113$. 